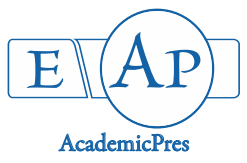

Mittal P et al. (2021)

Notulae Scientia Biologicae 13(1):10836

DOI: $10.15835 / \mathrm{nsb} 13110836$

Research Article

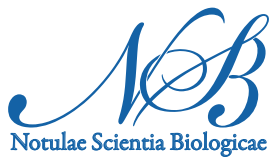

\title{
Bowman-Birk inhibitor in soybean: Genetic variability in relation to total trypsin inhibitor activity and elimination of Kunitz trypsin inhibitor
}

\author{
Priyanka MITTAL ${ }^{1}$, Vineet KUMAR ${ }^{1 *}$, Anita RANI ${ }^{1}$, S.M. GOKHALE ${ }^{2}$ \\ ${ }^{1}$ ICAR-Indian Institute of Soybean Research, Khandwa road, Indore, M.P., 452001, India; \\ mittal.priyanka9@gmail.com; vineetksahni@yahoo.com (correspondingauthor); anitavks@yahoo.co.in \\ ${ }^{2}$ School of Biochemistry, Devi Ahilya Vishwavidhyalaya, Khandwa Road, Indore, Madhya Pradesh, 452001, \\ India;gokhale.drsm@gmail.com
}

\begin{abstract}
Bowman-Birk inhibitor (BBI) is a soybean seed serine protease inhibitor whose nutraceutical properties far exceed its anti-nutritional property arising from its trypsin and chymotrypsin inhibitor activity. High BBI soybean genotypes are sought for the commercial preparation of this nutraceutical biomolecule while low BBI content in Kunitz trypsin inhibitor (KTI)-free genetic background is desirable in soymeal manufacturing. In the present investigation, monoclonal antibody assay of 95 soybean genotypes revealed 11fold genetic variation for BBI concentration. The study led to the identification of 3 very high $(>20 \mathrm{mg} / \mathrm{g}$ defatted soy flour) and 5 very low BBI $(<4 \mathrm{mg} / \mathrm{g}$ defatted soy flour) soybean genotypes. Contribution of BBI to total trypsin inhibition activity ranged from 2.2 to $53.5 \%$ with average value of $11.6 \%$. Genotypes with varying level of $\mathrm{BBI}$ raised consecutively for two years exhibited non-significant $(p>0.05)$ effect of growing year on the trait. $\mathrm{BBI}$ content in $\mathrm{BC}_{3} \mathrm{~F}_{2}$ derived KTI-free lines was at par with the recurrent parent. Low and high BBI content genotypes with diverse genetic background identified in the study may be exploited to develop mapping population to identify genomic regions underlying BBI in soybean.
\end{abstract}

Keywords: Bowman-Birk inhibitor; genetic variability; Kunitz trypsin inhibitor; total trypsin inhibitor

\section{Introduction}

Kunitz trypsin inhibitor (KTI) and Bowman-Birk inhibitor (BBI) are two major serine protease inhibitors in soybean seeds, accounting for nearly $6 \%$ fraction of total soluble protein. KTI, $21 \mathrm{kDa}$ polypeptide with 181 amino acids, is an anti-nutritional factor (ANF) in soybean seeds as it inhibits trypsin to the magnitude of 2.51 times of its own concentration (Kumar et al., 2018), thereby interfering with the digestion of proteins in human gastrointestinal tract (GIT). Various physical and biological methods, namely, boiling, autoclaving, pulse electric field, microwave irradiation and sprouting are being used by soy industries for the inactivation of this ANF (Dia et al., 2012; Chen et al., 2014; Kumar et al., 2019). Though, plant breeders have developed KTI free soybean genotypes through marker assisted and traditional plant breeding using soybean germplasm accession with null allele of KTI (Peric et al., 2011; Kumar et al., 2015; AICRPS, 2018). BBI is a

Received: 26 Oct 2020. Received in revised form: 18 Feb 2021. Accepted: 24 Feb 2021. Published online: 05 Mar 2021.

From Volume 13, Issue 1, 2021, Notulae Scientia Biologicae journal will use article numbers in place of the traditional method of continuous pagination through the volume. 
low molecular weight $(8 \mathrm{kDa})$, double headed serine protease inhibitor, with 71 amino acids in its polypeptide chain which can inhibit trypsin and chymotrypsin simultaneously (Odani and Ikenaka, 1977). However, in view of several reports which demonstrated the role of $\mathrm{BBI}$ in suppressing carcinogenesis in animal models, $\mathrm{BBI}$ concentrate (BBIC) was given the status of Investigational New Drug (IND) by Food and Drug Association (FDA) way back in 1992 (Kennedy, 1993). Research works spanning across the past three decades have revealed chemo-preventive nutraceutical and cosmeceutical properties of BBI. BBIC has been reported to prevent the initiation of tumors and cause cell death in in vivo and invitro cancer models (Kennedy, 1998; Kennedy and Wan, 2002). Besides its chemo-preventive and anti-inflammatory properties (Clemente et al.,2011), BBI has been recently reported to be effective in the treatment of Alzheimer's disease (Akbari et al., 2019) and inhibition of HIV replication in macrophages (Ma et al., 2016). Further, in the backdrop of the fact that SARSCoV-2, the causative agent of COVID-19 pandemic, requires the expression of self-encoded chymotrypsin-like protease for its replication in the host cell (Cascella et al., 2020), BBI in soybean may show an inhibitory effect on the multiplication of this novel virus in human cell due to its chymotrypsin inhibiting property. Further, the cosmeceutical application of BBI stems from its role in preserving skin health, weight-loss and anti-alopecia (Losso, 2010). Therefore, soybean varieties with high level of BBI are much sought after commodity as raw material for manufacturing commercial formulations.

Assessment of the genetic variability of BBI in the soybean cultivars/ promising germplasm lines is the first prerequisite to initiate plant breeding programme focusing on the development of high BBI soybean varieties. On the other hand, heat treatment required to render chymotrypsin and trypsin inhibiting activity of BBI dysfunctional, along with trypsin inhibiting activity of KTI, incurs extra cost in soymeal manufacturing. This necessitates the development of low BBI soybean genotypes in the KTI-free genetic background for use in soymeal industry. Though, investigations regarding the estimation of BBI concentration in soybean have been reported but these studies are not only scarce but the genotypes undertaken in them were also very few. Brandon et al. (2004) reported BBI in the range of $0.7-5.5 \mathrm{mg} / \mathrm{g}$ soy meal in 11 wild soybean germplasm using sensitive monoclonal antibody-based ELISA method. Pesic et al. (2007) determined BBI concentration in 12 soybean cultivars, and reported a range of $0.6-6.32 \%$ of total extractable protein using polyacrylamide gel electrophoresis. Kumar et al. (2018) determined BBI content in 7 Indian soybean varieties and reported a range of $7.4-23.4 \mathrm{mg} / \mathrm{g}$ defatted soy flour using monoclonal antibody-based ELISA method. KTI is primarily responsible for trypsin inhibitor activity (TIA) of soybean seeds; however, a wide genotypic variation was reported with regard to its contribution to total TIA (Kumar et al., 2019). Therefore, a variation may also exist with regard to percent contribution of BBI to total TIA activity across 90 commercially released soybean varieties undertaken in the study. As mentioned above, KTI free soybean genotypes with low BBI serve as excellent raw material for the soymeal manufacturing. However, Gillman et al. (2015) reported enhancement in BBI concentration in a KTI free $\mathrm{F}_{2}$ line (E16) at early seed stage obtained by crossing 'PI68679' (null KTII) with 'PI542044' (null KTI3), though the null KTI3 was solely responsible for the absence of KTI. This observation was untenable because a $\mathrm{F}_{2}$ line may be segregating for several $\mathrm{BBI}$ loci. In contrast to the segregating $\mathrm{F}_{2}$ line undertaken for investigation pertaining the effect of genetic removal of KTI on BBI by these authors, $5 \mathrm{BC}_{3} \mathrm{~F}_{2}$ derived KTI free lines of the cross 'JS97-52' x 'PI542044' (exhibiting more than $96 \%$ recurrent parent genomic content) were analysed. Moreover, the seed composition of the soybean is reported to be influenced by the growing environment as suggested in multi-location and staggered planting date experiments (Kumar et al., 2006a; Kumar et al., 2006b). Therefore, in the present study it was thought worthwhile to determine BBI content in large number of soybean genotypes (95), to determine the genetic variability for the trait and identify soybean genotypes with high and low levels of BBI in different genetic background, and to investigate the effect of growing year on BBI content by analyzing the harvest of these high and low BBI soybean genotypes obtained in the cropping season of two consecutive years. 


\section{Materials and Methods}

\section{Experimental data}

Ninety-five soybean genotypes were raised in cropping season (last week of June to mid week of October) 2018 in the fields of ICAR-Indian Institute of Soybean Research, Indore (N 22.7196 and E $75.8577^{\circ}$ ), Madhya Pradesh, India. The geographic coordinates of the site of field crop was N $22.7196^{\circ}$ and E $75.8577^{\circ}$ and located in the Central zone, which is the major agroclimatic zone for commercial cultivation of soybean in India. Of the 95 genotypes, 89 were the soybean varieties released for commercial cultivation in the country by All India Co-ordinated Research Project on Soybean, India. Five genotypes were KTI-free breeding lines derived from $\mathrm{BC}_{3} \mathrm{~F}_{2}$ generation of the cross 'JS97-52' (recurrent parent) $\times$ 'PI542044', with > 96\% recurrent parent genome content (RPGC). One genotype 'NRC101' was a KTI free breeding line developed through marker assisted forward breeding from the cross 'Samrat' $\times$ 'PI542044'. The soil of the field where the soybean genotypes were raised was vertisol. Genotypes were planted in triplicate in single row plot of $3 \mathrm{~m}$ length with row-to-row and plant-to-plant distance of 45 and $5 \mathrm{~cm}$, respectively, in random block design using standard agronomic practices recommended for cultivation of soybean in Central India.

\section{Extraction and estimation of BBI concentration through indirect ELISA}

Finely ground soybean flour ( 60 mesh) was defatted using petroleum ether (boiling point $40-60{ }^{\circ} \mathrm{C}$ ). Defatted soy flour $(50 \mathrm{mg})$ was suspended in $1 \mathrm{ml}$ of $50 \mathrm{mM}$ Tris buffer $(\mathrm{pH} 8.2)$ and homogenized using Polytron homogenizer (Kinematica, Model PT2100, Switzerland) followed by ultra-sonication (Pci Analytics) for $1 \mathrm{~h}$. During ultrasonication, samples were vortexed after every $15 \mathrm{~min}$. The suspension so obtained was centrifuged at 20,000 g for $35 \mathrm{~min}$ at $4{ }^{\circ} \mathrm{C}$ and the supernatant was diluted 25,000 times using phosphate buffered saline. Standard curve $\left(y=0.03 x+0.3146, R^{2}=0.996\right)$ was generated using varying concentration of purified BBI.

Extracted samples were dispensed in triplicate in 96-well maxisorb nunc immunoplates $(100 \mu l$ in each well) for overnight $\left(15-18 \mathrm{~h}\right.$ ) incubated at $4{ }^{\circ} \mathrm{C}$. Incubation was followed by repeated washing ( $4-5$ times) with buffer (PBS $+0.05 \%$ Tween 20). Subsequently, $250 \mu \mathrm{l}$ of blocking buffer ( $5 \%$ bovine serum albumin $+1 \%$ Tween 20 in PBS) was added and incubated for $2 \mathrm{~h}$ (with interval shaking) at $37^{\circ} \mathrm{C}$ followed by $4-5$ washings. A $50 \mu \mathrm{l}$ of diluted (1:1000 in 3\% BSA buffer solution) BBI primary antibody was dispensed into each well and incubated for $2 \mathrm{~h}$ with 1 shaking after every $10 \mathrm{sec}$. After washing, $50 \mu \mathrm{l}$ of diluted (1:1000 in 3\% BSA buffer) alkaline phosphatase conjugated anti-mouse antibody was added to each well and incubated for $1 \mathrm{~h}$ at room temperature. Unbound conjugated anti-mouse antibodies were removed by repeated washing followed by addition of $100 \mu \mathrm{l}$ p-nitrophenyl phosphate (pNPP). The plate was immediately sealed with black polyvinyl seal and incubated at $37^{\circ} \mathrm{C}$. Reaction was stopped at $30 \mathrm{~min}$ using $3 \mathrm{~N} \mathrm{NaOH}$. Absorbance was recorded using ELISA plate reader (Multiscan Go-Thermo Scientific Pvt Ltd, United States) at $405 \mathrm{~nm}$.

\section{BBI activity}

The trypsin inhibition activity of BBI was calculated as half of the BBI concentration as per the information provided in product analysis note in BBI standard (T9777) procured from Sigma Aldrich Pvt Ltd India.

\section{Statistical analysis}

All the steps and assays were performed in triplicate samples with satisfactory repetition of values. Data presented in Tables 1 and 2 are mean \pm standard deviation of three independent replicates. All the statistical analyses were carried out through $S A S 9.3$ with significance at $p<0.05$. 


\section{Results}

Table 1 presents the data of BBI concentration in 90 soybean genotypes, comprising of 89 commercial soybean varieties and one advanced breeding KTI-free line ('NRC101'), grown in India in cropping season of 2018, while Table 2 gives BBI concentration in $5 \mathrm{KTI}$-free $\mathrm{BC}_{3} \mathrm{~F}_{2}$ derived lines, which included first KTI-free soybean variety NRC127, developed by introgression null allele of KTI in variety 'JS97-52' through marker assisted backcrossing, released for commercial cultivation in India (AICRPS, 2018). BBI concentration in 90 varieties ranged from 2.2 ('RAUS5') to $24.5 \mathrm{mg} / \mathrm{g}$ defatted soy flour ('JS79-81'), with 11-fold variation and average value of $9.07 \mathrm{mg} / \mathrm{g}$ defatted soy flour. Further, the frequency distribution of BBI concentration across 90 genotypes showed skewness and kurtosis of 0.595 and -2.5 , respectively, indicating that the data obtained was fairly symmetrical with least number of genotypes in extreme ranges. Further, this range was divided into 5 different classes: very low (<4 mg/g defatted soy flour), low (4-8 mg/g defatted soy flour), moderate (8-15 $\mathrm{mg} / \mathrm{g}$ defatted soy flour), high $(15-20 \mathrm{mg} / \mathrm{g}$ defatted soy flour) and very high $(>20 \mathrm{mg} / \mathrm{g}$ defatted soy flour) (Figure 1). This classification showed that the highest number (39) of cultivars was in moderate BBI category followed by low BBI category (38). However, only three cultivars, namely, JS79-81 (24.5 mg/g defatted soy flour), JS90-41 (23.5 mg/g defatted soy flour) and PS1241 (22.0 mg/g defatted soy flour) exhibited very high BBI concentration while 5 cultivars, namely, RAUS $5(2.2 \mathrm{mg} / \mathrm{g}$ defatted soy flour), VLS47 (2.7 mg/g defatted soy flour), VLS2 (3.1 mg/g defatted soy flour), PUSA16 (3.6 mg/g defatted soy flour) and DS228 (3.7 mg/g defatted soy flour) exhibited very low BBI concentration $(<4.0 \mathrm{mg} / \mathrm{g}$ defatted soy flour).

Table 1. Genotypic variation of BBI conc. ( $\mathrm{mg} / \mathrm{g}$ defatted soy flour) in soybean varieties and its contribution to TIA

\begin{tabular}{|c|c|c|c|c|c|c|c|c|c|}
\hline Variety & Zone & $\mathrm{BBI}^{1}$ & $\begin{array}{c}\text { BBI } \\
\text { activity }\end{array}$ & $\begin{array}{c}\% \\
\text { contribution } \\
\text { to TIA }\end{array}$ & Variety & $\mathrm{BBI}^{1}$ & Zone & BBI activity & $\begin{array}{c}\% \\
\text { contribution } \\
\text { to TIA }\end{array}$ \\
\hline ADT-1 & SZ & $6.0^{a} \pm 0.3$ & 3 & 8.5 & MAUS 32 & $10.1^{\mathrm{b}} \pm 0.48$ & SZ & 5.1 & 18.6 \\
\hline Alankar & NPZ & $9.6^{b} \pm 0.43$ & 4.8 & 14.4 & NRC2 & $11.3^{\mathrm{b}} \pm 0.50$ & $\mathrm{CZ}$ & 5.65 & 24.1 \\
\hline Birsa soybean & NPZ & $4.5^{a} \pm 0.27$ & 2.25 & 3.9 & NRC 37 & $19.7^{d} \pm 0.78$ & $\mathrm{CZ}$ & 9.85 & 53.5 \\
\hline Bragg & $\mathrm{CZ}$ & $5.8^{a} \pm 0.23$ & 2.9 & 8.5 & NRC7 & $9.9^{\mathrm{b}} \pm 0.34$ & $\mathrm{CZ}$ & 4.95 & 14.1 \\
\hline $\mathrm{Co}-1$ & SZ & $5.1^{a} \pm 0.31$ & 2.55 & 5.8 & NRC12 & $13.5^{c} \pm 0.43$ & $\mathrm{CZ}$ & 6.75 & 14.6 \\
\hline Co Soya-2 & SZ & $9.01^{b} \pm 0.39$ & 4.51 & 11.2 & NRC86 & $12.4^{c} \pm 0.60$ & $\mathrm{CZ}$ & 6.2 & 13.3 \\
\hline Co-3 & SZ & $7.6^{\mathrm{b}} \pm 0.33$ & 3.8 & 11.3 & NRC101 & $7.5^{a} \pm 0.42$ & $\mathrm{CZ}$ & 3.75 & 23.4 \\
\hline DS 228 & SZ & $3.7^{a} \pm 0.09$ & 1.85 & 4.3 & PRS 1 & $16.4^{c} \pm 0.69$ & $\mathrm{CZ}$ & 8.2 & 23.4 \\
\hline Pusa97-12 & NPZ & $5.2^{a} \pm 0.30$ & 2.6 & 4.5 & Pusa16 & $3.6^{a} \pm 0.17$ & NPZ & 1.6 & 2.56 \\
\hline Davis & SZ & $11.1^{\mathrm{b}} \pm 0.51$ & 5.55 & 14.2 & Pusa20 & $5.0^{a} \pm 0.20$ & NPZ & 2.5 & 4.6 \\
\hline $\begin{array}{c}\text { Gujrat } \\
\text { soybean } 1 \\
(\mathrm{~J} 231)\end{array}$ & SZ & $10.7^{b} \pm 0.49$ & 5.35 & 16.4 & Pusa24 & $6.2^{\mathrm{a}} \pm 0.30$ & NPZ & 3.1 & 9.6 \\
\hline $\begin{array}{c}\text { Gujrat } \\
\text { soybean } 2 \\
(\mathrm{~J} 202)\end{array}$ & SZ & $17.5^{\mathrm{d}} \pm 0.53$ & 8.75 & 22.3 & Pusa 98-14 & $7.2^{b} \pm 0.33$ & NPZ & 3.6 & 6.7 \\
\hline $\begin{array}{c}\text { Harit soy } \\
\text { (Hims1563) }\end{array}$ & $\mathrm{NHZ}$ & $12.6^{c} \pm 0.56$ & 6.3 & 12.7 & PK471 & $5.4^{\mathrm{a}} \pm 0.22$ & NPZ & 2.7 & 6.9 \\
\hline Hardee & SZ & $9.8^{\mathrm{b}} \pm 0.63$ & 4.9 & 12.8 & Palam soya & $8.5^{b} \pm 0.51$ & NHZ & 4.25 & 9.9 \\
\hline Indira soya 9 & NEZ & $7.44^{b} \pm 0.40$ & 3.72 & 7.5 & PK 327 & $10.2^{b} \pm 0.46$ & NPZ & 5.1 & 6.8 \\
\hline $\begin{array}{c}\text { Improved } \\
\text { Pelican }\end{array}$ & SZ & $5.2^{\mathrm{a}} \pm 0.30$ & 2.6 & 5.6 & $\begin{array}{c}\text { Pratap Soya } \\
2\end{array}$ & $7.7^{b} \pm 0.32$ & NEZ & 3.85 & 6.1 \\
\hline JS20-34 & $\mathrm{CZ}$ & $12.5^{c} \pm 0.20$ & 6.25 & 9.7 & Pusa22 & $13^{c} \pm 0.44$ & NPZ & 6.5 & 8.5 \\
\hline JS 71-05 & $\mathrm{CZ}$ & $7.4^{\mathrm{b}} \pm 0.32$ & 3.7 & 8.6 & Punjab1 & $9.9^{\mathrm{b}} \pm 0.37$ & NPZ & 4.95 & 26.6 \\
\hline JS72-44 & $\mathrm{CZ}$ & $4.7^{\mathrm{a}} \pm 0.19$ & 1.7 & 4.5 & Pusa40 & $13.4^{\mathrm{c}} \pm 0.72$ & NPZ & 6.7 & 13.8 \\
\hline JS76-205 & $\mathrm{CZ}$ & $9.5^{b} \pm 0.43$ & 4.75 & 8.3 & PK416 & $12.5^{\mathrm{c}} \pm 0.50$ & NPZ & 6.25 & 12.2 \\
\hline JS79-81 & SZ & $24.5 \pm 1.07$ & 12.25 & 31.6 & PS1042 & $6.1^{a} \pm 0.28$ & NPZ & 3.1 & 6.4 \\
\hline JS90-41 & $\mathrm{CZ}$ & $23.5 \pm 0.76$ & 11.75 & 31.8 & PS1024 & $5.1^{a} \pm 0.25$ & NPZ & 2.6 & 6.6 \\
\hline JS93-05 & $\mathrm{CZ}$ & $12.9^{c} \pm 0.39$ & 6.45 & 17.6 & PS 1225 & $12.7^{\mathrm{c}} \pm 0.40$ & NHZ & 6.35 & 18.4 \\
\hline JS95-60 & $\mathrm{CZ}$ & $12.7^{c} \pm 0.52$ & 6.35 & 16.9 & PS1029 & $6.3^{\mathrm{a}} \pm 0.31$ & NPZ & 3.15 & 6.2 \\
\hline JS97-52 & $\mathrm{CZ}$ & $7.4^{\mathrm{b}} \pm 0.55$ & 5.1 & 7.6 & PK472 & $13.4^{c} \pm 0.60$ & NPZ & 6.7 & 16.6 \\
\hline JS 335 & $\mathrm{CZ}$ & $6.9^{a} \pm 0.33$ & 3.45 & 7.9 & Ps564 & $7.4^{\mathrm{b}} \pm 0.22$ & NPZ & 3.7 & 7.2 \\
\hline JS2029 & $\mathrm{CZ}$ & $12.44^{c} \pm 0.59$ & 6.22 & 16.1 & PS1092 & $13.7^{\mathrm{c}} \pm 0.48$ & NPZ & 6.85 & 13.4 \\
\hline Kalitur & $\mathrm{CZ}$ & $8.4^{\mathrm{b}} \pm 0.54$ & 4.2 & 12.4 & PS1241 & $22.0^{c} \pm 0.76$ & NHZ & 11.0 & 19.4 \\
\hline KHSb2 & SZ & $5.9^{a} \pm 0.32$ & 2.95 & 6.1 & RVS2001-4 & $16.4^{c} \pm 0.73$ & $\mathrm{CZ}$ & 8.2 & 16.4 \\
\hline KB79 & SZ & $7.2^{\mathrm{b}} \pm 0.34$ & 3.6 & 7.9 & RKS24 & $11.0^{\mathrm{b}} \pm 0.50$ & $\mathrm{CZ}$ & 5.5 & 13.5 \\
\hline Lee & $\mathrm{NHZ}$ & $13.3^{c} \pm 0.61$ & 6.65 & 15.5 & RAUS5 & $2.2^{a} \pm 0.13$ & NEZ & 1.1 & 2.2 \\
\hline
\end{tabular}


Mittal P et al. (2021). Not Sci Biol 13(1):10836

\begin{tabular}{|c|c|c|c|c|c|c|c|c|c|}
\hline LSb1 & SZ & $13.3^{\mathrm{c}} \pm 0.67$ & 6.65 & 13.0 & Shilajeet & $8.1^{\mathrm{b}} \pm 0.38$ & $\mathrm{NHZ}$ & 4.1 & 8.5 \\
\hline MACS13 & SZ & $4.0^{a} \pm 0.28$ & 2 & 6.3 & SL96 & $6.6^{a} \pm 0.31$ & NPZ & 3.3 & 9.4 \\
\hline MACS57 & SZ & $5.8^{a} \pm 0.30$ & 2.9 & 6.2 & SL 688 & $6.4^{\mathrm{a}} \pm 0.30$ & NPZ & 3.2 & 6.6 \\
\hline MACS58 & SZ & $10.1^{b} \pm 0.49$ & 5.1 & 11.2 & Shivalik & $5.2^{a} \pm 0.20$ & $\mathrm{NHZ}$ & 2.6 & 7.4 \\
\hline MACS124 & SZ & $3.3^{a} \pm 0.12$ & 1.65 & 4.3 & SL295 & $11.9^{c} \pm 0.54$ & NPZ & 5.95 & 16.2 \\
\hline MACS450 & SZ & $11.7^{\mathrm{c}} \pm 0.44$ & 5.85 & 11.7 & SL525 & $10.3^{b} \pm 0.42$ & $\mathrm{NHZ}$ & 5.2 & 12.4 \\
\hline MAUS1 & SZ & $9.6^{b} \pm 0.43$ & 4.8 & 13.9 & TAMS 38 & $18.0^{\mathrm{d}} \pm 0.48$ & $\mathrm{CZ}$ & 9 & 21.8 \\
\hline MAUS2 & SZ & $9.0^{\mathrm{b}} \pm 0.37$ & 4.5 & 9.5 & $\begin{array}{c}\text { TAMS 98- } \\
21\end{array}$ & $4.2^{\mathrm{a}} \pm 0.18$ & $\mathrm{CZ}$ & 2.1 & 4.5 \\
\hline MAUS61 & $\mathrm{CZ}$ & $9.4^{\mathrm{b}} \pm 0.44$ & 4.7 & 11.1 & VLS1 & $4.7^{a} \pm 0.20$ & NHZ & 2.4 & 5.7 \\
\hline MAUS61-2 & $\mathrm{CZ}$ & $4.7^{a} \pm 0.23$ & 2.35 & 6.5 & VLS2 & $3.1^{a} \pm 0.18$ & NHZ & 1.6 & 2.3 \\
\hline MAUS71 & $\mathrm{CZ}$ & $4.2^{a} \pm 0.21$ & 2.1 & 3.3 & VLS21 & $12.3 \pm 0.54$ & $\mathrm{NHZ}$ & 6.15 & 10.1 \\
\hline MAUS158 & SZ & $12.5^{\mathrm{c}} \pm 0.57$ & 6.25 & 17.0 & VLS47 & $2.7^{\mathrm{a}} \pm 0.34$ & $\mathrm{NHZ}$ & 1.4 & 3.4 \\
\hline MAUS47 & $\mathrm{CZ}$ & $4.7^{\mathrm{a}} \pm 0.22$ & 2.35 & 5.0 & VL S63 & $7.1^{\mathrm{b}} \pm 0.21$ & $\mathrm{NHZ}$ & 3.6 & 6.7 \\
\hline MAUS81 & SZ & $7.1^{\mathrm{b}} \pm 0.47$ & 3.55 & 7.8 & VLS 65 & $5.5^{a} \pm 0.30$ & $\mathrm{NHZ}$ & 2.8 & 8.2 \\
\hline
\end{tabular}

*TIA value extracted from previously published study Kumar et al.2019

${ }^{1}$ Values given are mean of triplicate samples \pm SD. Values given with different superscripts are significantly $(p<0.05)$

different from each other

Table 2. BBI concentration ( $\mathrm{mg} / \mathrm{g}$ defatted soy flour) in KTI-free $\mathrm{BC}_{3} \mathrm{~F}_{2}$ lines

\begin{tabular}{|c|c|c|}
\hline $\mathrm{BC}_{3} \mathrm{~F}_{2}$ & $\mathrm{BBI}$ & KTI \\
\hline JS97-52 $(\mathrm{RP})$ & $7.4^{\mathrm{a}} \pm 0.32$ & KTI+ve \\
\hline NRC127 & $11.0^{\mathrm{a}} \pm 0.40$ & KTI-ve \\
\hline JSKTi9 & $7.7^{\mathrm{a}} \pm 0.30$ & KTI-ve \\
\hline JSKTi10 & $10.8^{\mathrm{a}} \pm 0.41$ & KTI-ve \\
\hline JSKTi11 & $10.4^{\mathrm{a}} \pm 0.40$ & KTI-ve \\
\hline JSKTi12 & $9.4^{\mathrm{a}} \pm 0.44$ & KTI-ve \\
\hline
\end{tabular}

${ }^{*}$ Note: Values given are mean of triplicate samples \pm standard deviation. Values given with different superscripts in the same column are significantly $(p<0.05)$ different from each other

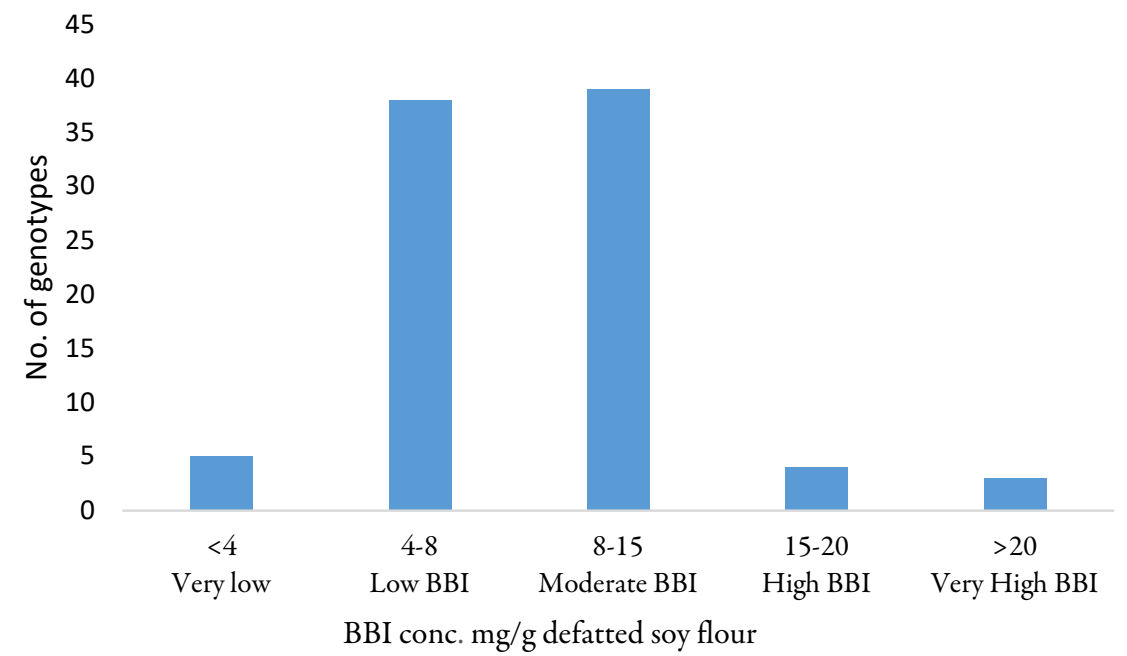

Figure 1. Distribution of 90 soybean varieties based upon varying BBI concentration 
Soybean cultivation area in India is divided into 5 major agroclimatic zones, namely, North East Hill Zone, Northern Hill Zone, North Plain Zone, Central Zone and Southern Zone, though majority of this area under soybean cultivation is Central Zone followed by Southern Zone. The varieties developed for different agroclimatic zones are best adapted to biotic and abiotic factors prevailing there. Average BBI content of varieties developed from North East Hill Zone was found minimum $(5.16 \mathrm{mg} / \mathrm{g}$ defatted soy flour) while average BBI content of from Central Zone was the highest $(12.6 \mathrm{mg} / \mathrm{g}$ defatted soy flour). The varieties developed from Northern Hill Zone and Northern Plain Zone exhibited almost same BBI concentration (7.5 and $7.7 \mathrm{mg} / \mathrm{g}$ defatted soy flour). Average BBI concentration of soybean varieties from Southern zone was slightly higher than North Plain zone and Northern Hill zone but significantly $(p<0.05)$ lower than the Central Zone. Further, BBI content among the most popular 7 Indian soybean varieties, namely, 'JS335', 'JS2034', JS20-29', 'JS95-60', 'JS93-05', 'RVS2001-4' and 'JS20-69', which account for 84\% of the total soybean breeder seed indent in the country (AICRPS, 2018) varied from $6.9 \mathrm{mg} / \mathrm{g}$ defatted soy flour (JS335) to 14.7 $\mathrm{mg} / \mathrm{g}$ defatted soy flour ('JS20-69').

Results presented in Table 2 gives $\mathrm{BBI}$ concentration in $\mathrm{KTI}$ free $\mathrm{BC}_{3} \mathrm{~F}_{2}$ derived lines from the cross 'JS97-52' (the recurrent parent) ×'PI542044' (the donor of null allele of KTI). Range of $9.4-11.0 \mathrm{mg} / \mathrm{g} \mathrm{defatted}$ soy flour for BBI concentration was noted among these 5 recombinant lines, thereby showing increase in BBI content compared to recurrent parent $(7.4 \mathrm{mg} / \mathrm{g}$ defatted soy flour) but this increase was statistically not significant $(p>0.05)$.

Table 3 gives BBI concentration of 7 soybean genotypes selected from very low (below 4), low (4-8), moderate (8-15) and high BBI concentration $(15-20 \mathrm{mg} / \mathrm{g}$ defatted soy flour) category raised for 2 years consecutively. Across all the 7 genotypes, no significant $(p>0.05)$ differences were noted for BBI concentration across two growing years despite the differences in weather parameters (refer Table 4). DS228 was in very low $\mathrm{BBI}$ concentration category in both first and second cropping year with non-significant differences for BBI concentration across two years. 'JSKTI9' in both the years was in low concentration category with no significant differences across 2 growing years. 'NRC127', which is a KTI free soybean variety, in moderate BBI concentration category did not register any significant change in BBI across two growing years. 'RVS2001-4' remained under high BBI concentration category with no significant changes in BBI concentration in both 2018 and 2019. On the other hand, 'NRC101', which is the KTI-free germplasm line developed from the cross 'Samrat' × 'PI542044', registered slightly higher value of BBI in 2019 than 2018, but statistically the values were not significantly different from each other. Both 'RAUS5' and 'VLS47' remained in very low concentration category in both the growing years. These results showed that the effect of growing year on BBI content was non-significant $(p>0.05)$.

Table 3. BBI concentration ( $\mathrm{mg} / \mathrm{g}$ defatted soy flour) of selected soybean genotypes across different growing years

\begin{tabular}{|c|c|c|}
\hline Genotype & 2018 & 2019 \\
\hline NRC101 & $7.5^{\mathrm{a}} \pm 0.42$ & $9.6^{\mathrm{a}} \pm 1.0$ \\
\hline RAUS 5 & $2.2^{\mathrm{a}} \pm 0.14$ & $3.9^{\mathrm{a}} \pm 0.38$ \\
\hline NRC127 & $11.0^{\mathrm{a}} \pm 0.87$ & $11.4^{\mathrm{a}} \pm 1.2$ \\
\hline DS228 & $3.2^{\mathrm{a}} \pm 0.26$ & $3.9^{\mathrm{a}} \pm 0.30$ \\
\hline RVS2001-4 & $16.4^{\mathrm{a}} \pm 1.3$ & $15.7^{\mathrm{a}} \pm 1.3$ \\
\hline VLS47 & $2.7^{\mathrm{a}} \pm 0.24$ & $3.8^{\mathrm{a}} \pm 0.41$ \\
\hline JSKTI9 & $7.7^{\mathrm{a}} \pm 0.36$ & $7.5^{\mathrm{a}} \pm 0.67$ \\
\hline
\end{tabular}

${ }^{*}$ Note: Values given are mean of triplicate samples \pm standard deviation. Values given with the same superscript in a row are statistically at par with each other $(p>0.05)$. 
Table 4. Average maximum, minimum and mean temperature (unit ${ }^{\circ} \mathrm{C}$ ), and rainfall (inches) in cropping season (last week of June to mid week of October) of 2018 and 2019.

\begin{tabular}{|c|c|c|}
\hline \multirow{2}{*}{ Weather parameter } & \multicolumn{2}{|c|}{ Growing year } \\
\cline { 2 - 3 } & 2018 & 2019 \\
\hline Average maximum temperature & 31.4 & 30.9 \\
\hline Average minimum temperature & 23.0 & 22.7 \\
\hline Average mean temperature & 27.25 & 26.8 \\
\hline Average rainfall & 31.4 & 53 \\
\hline
\end{tabular}

\section{Discussion}

Estimation of BBI concentration in large number of genotypes has not yet been reported, however, a few studies concerning genetic variation for the levels of BBI in selected number of soybean genotypes are available in the literature (Brandon et al., 2004; Pesic et al., 2007' Kumar et al., 2018). Among 11 wild soybean germplasms, Brandon et al. (2004) reported 7.8-fold variation in the concentration of this polypeptide with a range of $0.7-5.5 \mathrm{mg} / \mathrm{g}$ defatted soy flour. Pesic et al. (2007) investigated 12 soybean cultivars for BBI concentration including one KTI free genotype and the BBI concentration reported in the study was $1.79 \%$ of total extractable protein. Assuming average 39\% protein content and maximum $80 \%$ extractable protein in soybean, $1.79 \%$ of extractable protein will be equivalent to $5.6 \mathrm{mg} / \mathrm{g}$ of flour which is much lesser than the average BBI content $(9.07 \mathrm{mg} / \mathrm{g}$ defatted soy flour) in our study. Pauchar-Menacho et al. (2010) reported 5.9 $\mathrm{mg} / \mathrm{g}$ flour BBI concentration in the variety BRS133 which corresponds to the low BBI category in the present study. Kumar et al. (2018) investigated 7 Indian soybean cultivars for BBI content, and reported a range of 7.4 - $23.4 \mathrm{mg} / \mathrm{g}$ defatted soy flour. In the present study, we identified 5 soybean genotypes which exhibited BBI concentration below $4 \mathrm{mg} / \mathrm{g}$ defatted soy flour and 3 genotypes with BBI concentration between $22-25 \mathrm{mg} / \mathrm{g}$ defatted soy flour. Introgression of null allele of KTI in very low BBI genotypes through marker assisted backcrossing $(\mathrm{MABC})$ may be used for the development of soybean cultivars with the lowest TIA value, which would be excellent raw material for soymeal manufacturing industry.

\section{Contribution of BBI to total TIA}

Though, KTI has been reported to account for $1-79.8 \%$ of the total TIA with average value of $52.8 \%$ recently (Kumar et al., 2019), however, no information pertaining to the contribution of BBI to total TIA is available in literature. As both soybean cultivars (90) and the seed lot from which they were drawn for the investigation of BBI concentration in the present study and Kumar et al. (2019) were same, the TIA data reported in the latter study was used to compute the contribution of BBI to total TIA. As evident from Table 1 , significant $(p<0.05)$ varietal differences were observed for contribution of BBI to total trypsin inhibitor activity (TIA), which ranged from 2.2 ('RAUS5') to $53.5 \%$ ('NRC37') with $11.6 \%$ average contribution to TIA. High BBI varieties, namely, 'JS79-81' and 'JS90-41' contributed 31.6 and $31.8 \%$ while low BBI genotypes 'RAUS5', 'VLS2' and 'Pusa16' contributed 2.2, 2.3 and 2.6\% to total TIA, respectively. Further, 'Punjab1' showed low BBI concentration to the magnitude of $4.95 \mathrm{mg} / \mathrm{g}$ defatted soy flour but contributed $26.6 \%$ of TIA, while 'NRC37' which has same level ( $4.95 \mathrm{mg} / \mathrm{g}$ defatted soy flour) of BBI activity but accounted for 14\% of TIA. This may be attributed to very low level of KTI activity in 'Punjabl' as reported in our recent study (Kumar et al., 2019). Further, higher BBI concentration in cultivar 'NRC37' (14.8 mg/g defatted soy flour) than its parents cultivars 'JS72-44' ( $4.7 \mathrm{mg} / \mathrm{g}$ defatted soy flour) and 'Punjab1" ( $9.9 \mathrm{mg} / \mathrm{g}$ defatted soy flour) and similarly, higher BBI concentration of 'PK1092' (13.7 mg/g defatted soy flour) than its parents 'PK327' $(10.2 \mathrm{mg} / \mathrm{g}$ defatted soy flour) and 'PK 416 ' (12.5 mg/g defatted soy flour) showed the transgressive segregation for this trait (Deshimaru et al., 2004). 


\section{Effect of genetic removal of KTI on BBI}

In international market, soybean meal is traded with stringent norms pertaining to the level of total trypsin inhibitor activity, which is brought down to the desirable benchmark $(<10 \mathrm{mg} / \mathrm{g}$ soymeal $)$ by heattreatment during manufacturing. To obviate the need of this cost-incurring in heat treatment, soybean genotypes genetically free from KTI, which contributes primarily to TIA, have been developed by the plant breeders (Peric et al., 2011; Kumar et al., 2015; AICRPS 2018). However, in these KTI free genotypes, BBI is also sought to be low so that total TIA is below the international limit of soymeal in the seed (raw material) itself which would save the cost incurring in the heat treatment. This necessitates investigation pertaining to the effect of genetic removal of KTI on the concentration of BBI. Friedman et al. (1991) investigated BBI in a KTI free cultivar derived from 'Williams 82' through back crossing and showed BBI concentration at par with the parent genotype ('Williams-82'). Gillman et al. (2015) investigated the effect of genetic removal of the KTI from 'Williams 82'. The authors reported overproduction of BBI in a KTI free $F_{2}$ line 'E 16 ' compared to wild type and suggested that the tot proteome was rebalanced itself by a dramatic increase in the levels of $\mathrm{BBI}$ on the genetic removal of KTI. Therefore, both the above-mentioned studies gave contrasting results. Five $\mathrm{BC}_{3} \mathrm{~F}_{2}-$ derived KTI free soybean genotypes developed by introgression of null allele of KTI from 'PI542044' in Indian soybean variety 'JS97-52' (Kumar et al., 2015) were analyzed for BBI content in the present study and the results are presented in Table 2. Numerically, the data showed higher $\mathrm{BBI}$ content in $\mathrm{BC}_{3} \mathrm{~F}_{2}$ derived $\mathrm{KTI}$ free breeding lines compared to recurrent parent, however statistically the values of the former were not significantly different from the latter. Therefore, assessment of $5 \mathrm{BC}_{3} \mathrm{~F}_{2}$ derived KTI free lines along with the recurrent parent showed that the genetic removal of KTI did not impact BBI concentration significantly in contrast to the study of Gillman et al. (2015) but in consonance with Friedman et al. (1991).

\section{Pedigree analysis}

Pedigree of low BBI genotypes, namely, 'DS228', 'VLS47', 'VLS2', 'RAUS5' was scrutinized. 'RAUS5' was developed from 'Pusa16' $\times$ 'JS335'. It was interesting to note that Pusa16, the female parent of 'RAUS5', also showed low BBI activity ( $1.6 \mathrm{mg} / \mathrm{g}$ defatted soy flour) (Table 1). 'DS228' is a genotype developed from the cross 'JS335' × 'DS181', 'VLS47' is a selection from 'KHSF3-1' and 'VLS2' is selection from 'VHC 856007'. Therefore, 'DS228' and 'RAUS5' both the low BBI genotypes are genetically close, as both have a common parent ('JS335'). Two high BBI content varieties, namely, 'JS79-81' and 'JS90-41' are genetically diverse as the former was developed from the cross 'Bragg' × 'Harosoy-Deciduous' while the latter from the cross 'PS73-7' $\times$ 'Hark'. Further, the information regarding the identification of genomic regions governing the biosynthesis of BBI content in soybean seeds is scarce (de Almeida Barros et al., 2012). Therefore, the crossing between high and low BBI genotypes, such as 'DS228'/'RAUS5' × 'JS79-81'/ 'JS90-41', 'VLS2'/'VLS47' × 'JS79-81'/'JS9041 ' may be effected to develop mapping population to identify QTLs associated with BBI in soybean and to develop novel genotypes which may have BBI more than the maximum value $(24.5 \mathrm{mg} / \mathrm{g}$ defatted soy flour) observed in the present study. Furthermore, BBI in soybean have been reported to have several isoforms, which differ in molecular weight and substrate specificity (Tan-Wilson et al., 1987). Of the $5 \mathrm{BBI}$ isoforms, namely, BBI-A, BBI-B, BBI-CII, BBI-DII and BBI-E1 identified in soybean cultivars (Deshimaru et al., 2004), BBI-A, BBI-CII and BBI-DII are the major isoforms with different substrate specificity as both BBI-B and BBI-A possess similar amino acid composition and specificity while BBI-EI and BBI-DII lack nine amino acid residue at $\mathrm{N}$-terminal region. It would be interesting to investigate which isoforms correspond to low and high $\mathrm{BBI}$ content genotypes identified in the present study and exploit the information in designing breeding programme for developing novel high and low BBI soybean genotypes. 


\section{Conclusions}

In brief, this is the first report pertaining to the estimation of $\mathrm{BBI}$ in large number of soybean genotypes to assess its genetic variation and contribution to total TIA. The investigation revealed 11-fold genetic variability for the trait and led to the identification of very low and very high BBI content soybean genotypes, which did not show significant $(p>0.05)$ variation across two growing years. The magnitude of contribution of BBI to total TIA was genotype-dependent. Our results also showed that genetic removal of KTI in soybean did not impact BBI content significantly. High BBI genotypes identified in the study can serve as excellent raw material for the nutraceutical industry while low BBI genotypes may be crossed with null KTI genotypes to develop genotypes with negligible level of total TIA required for soymeal industry. The genotypes with extreme values of BBI content and diverse genetic background may be used for developing mapping population to identify genomic regions underlying BBI content in soybean.

\section{Authors' Contributions}

Conceptualization: VK and AR; Investigation: PM; Data curation: VK and PM; Methodology: VK, AR and PM; Supervision: SMG and VK; Writing original draft: VK and PM; Writing-review and editing: PM, VK, AR and SMG. All authors read and approved the final manuscript.

\section{Acknowledgements}

We thank ICAR-Indian Institute of Soybean Research, Indore for providing the farmland and laboratory facilities. This work was financially supported by University Grant Commission of India [421/ (CSIR-UGC NET DEC. 2018). Authors also thank Dr. Surendra Kumar, Information and Documentation officer, ICAR- Indian Institute of Soybean Research, for providing the local weather data of years 2018 and 2019

\section{Conflict of Interests}

The authors declare that there are no conflicts of interest related to this article.

\section{References}

AICRPS (2018). Proceeding of 48th annual group meet of the 'All India Coordinated Research Project on Soybean (AICRPS)' held from March $15^{\text {th }}$ to March $18^{\text {th }}, 2018$ at Raipur.

Akbari S, Akrami H, Mostafaei A, Kiani S (2019). Bowman-Birk inhibitor modifies transcription of autophagy and apoptosis genes in an in vitro model of Alzheimer's disorder. Journal of Cellular Biochemistry 120(7):1115011157. https://doi.org/10.1002/jcb.28391

Brandon DL, Bates AH, Friedman M (2004). Immunoassays for Bowman-Birk and Kunitz soybean trypsin inhibitors in infant formula. Journal of Food Science 69(1):11-15. https://doi.org/10.1111/j.1365-2621.2004.tb17849.x

Cascella M, Rajnik M, Cuomo A, Dulebohn SC, Napoli RD (2020). Features, evaluation and treatment of Coronavirus (COVID-19). Statpearl Publishing. 
Chen Y, Xu Z, Zhang C, Kong X, Hua Y (2014). Heat induced inactivation mechanism of Kunitz trypsin inhibitor and Bowman-Birk inhibitor in soymilk processing. Food Chemistry 154:108-116. https://doi.org/10.1016/j.foodchem.2013.12.092

Clemente A, Sonnante G, Domoney C (2011). Bowman-Birk inhibitors from legumes and human gastrointestinal health: current status and perspectives. Current Protein and Peptide Science 12(5):358-373. https://doi.org/10.2174/138920311796391133

De Almeida Barros B, da Silva W, Moreira M, de Barros E (2012). In silico characterization and expression analysis of the multigene family encoding the Bowman-Birk protease inhibitor in soybean. Molecular Biology Reports 39(1):327334.

Deshimaru M, Yoshimi S, Shioi S, Terada S (2004). Multigene family for Bowman-Birk type proteinase inhibitors of wild soja and soybean: the presence of two BBI-A genes and pseudogenes. Bioscience, Biotechnology and Biochemistry 68(6):1279-1286. https://doi.org/10.1271/bbb.68.1279

Dia VP, Gomez T, Vernaza G, Berhow M, Chang YK, Gonzalez de Mejia E (2012). Bowman-Birk and Kunitz protease inhibitors among antinutrients and bio-actives modified by germination and hydrolysis in Brazilian soybean cultivar BRS133. Journal of Agricultural and Food Chemistry 60:7886-7894. https://doi.org/10.1021/jf301926w

Friedman M, Brandon DL, Bates AH, Hymowitz T (1991). Comparison of a commercial soybean cultivar and an isoline lacking the Kunitz trypsin inhibitor: composition, nutritional value, and effects of heating. Journal of Agricultural and Food Chemistry 39(2):327-335. https://doi.org/10.1021/jfo0002a022

Gillman J, Kim W, H.B. Krishnan (2015). Identification of a new soybean Kunitz trypsin inhibitor mutation and its effect on Bowman-Birk protease inhibitor content in soybean seed. Journal of Agricultural and Food Chemistry 63(5):1352-1359. https://doi.org/10.1021/jf505220p

Kennedy AR, Szuhaj BF, Newberne PM, Billings PC (1993). Preparation and production of a cancer chemopreventive agent Bowman-Birk inhibitor concentrate. Nutrition and Cancer 19:281-302. https://doi.org/10.1080/01635589309514259

Kennedy AR (1998). The Bowman-Birk inhibitor from soybeans as an anticarcinogenic agent. The American Journal of Clinical Nutrition 68(6):1406S-1412S. https://doi.org/10.1093/ajcn/68.6.1406S

Kennedy AR, Wan XS (2002). Effects of the Bowman-Birk inhibitor on growth, invasion, and clonogenic survival of human prostate epithelial cells and prostate cancer cells. The Prostate 50(2):125-133. https://doi.org/10.1002/pros.10041

Kumar V, Rani A, Pandey V, Mande P (2006a). Compositional traits of soybean seeds as influenced by planting date in India. Experimental Agriculture 42(1):19-28. https://doi.org/10.1017/S0014479705003042

Kumar V, Rani A, Solanki S, Hussain SM (2006b). Influence of growing environment on the biochemical composition and physical characteristics of soybean seed. Journal of Food Composition and Analysis 19:188-195. https://doi.org/10.1016/j.jfca.2005.06.005

Kumar V, Rani A, Rawal R, Mourya V (2015). Marker assisted accelerated introgression of null allele of Kunitz trypsin inhibitor in soybean. Breeding Science 65(5):447-452. https://doi.org/10.1270/jsbbs.65.447

Kumar V, Rani A, Shuaib M, Mittal P (2018). Comparative assessment of trypsin inhibitor vis-à-vis Kunitz trypsin inhibitor and Bowman-Birk Inhibitor activities in soybean. Food Analytical Methods 11:2431-2437. https://doi.org/10.1007\%2Fs12161-018-1227-9

Kumar V, Rani A, Mittal P, Shuaib M (2019). Kunitz trypsin inhibitor in soybean: Contribution to total trypsin inhibitor activity as a function of genotype and fate during processing. Journal of Food Measurement and Characterization 13(2):1593-1590.

Losso JN (2010). The biochemical and functional food properties of Bowman Birk inhibitor. Critical Reviews in Food Science and Nutrition 48(1):94-118. https://doi.org/10.1080/10408390601177589

Ma TC, Zhou RH, Wang X, Li JL, Sang M, Zhou L, Hou W, Ho WZ (2016). Soybean-derived Bowman-Birk Inhibitor (BBI) inhibits HIV replication in macrophages. Scientific Reports 6:34752. https://doi.org/10.1038/srep34752

Odani S, Ikenaka T (1977). Studies on soybean trypsin inhibitors. X. Isolation and partial characterization of four soybean double-headed proteinase inhibitors. The Journal of Biochemistry 82:1513-1522. https://doi.org/10.1093/oxfordjournals.jbchem.a131845

Pauchar-Menacho LM, Berhow MA, Mandarino JMG, de Mejia EG, Chang YK (2010). Optimization of germination time and temperature on the concentration of bioactive compounds in Brazilian soybean cultivar BRS 133 using response surface methodology. Food Chemistry 119:636-642. https://doi.org/10.1016/j.foodchem.2009.07.011 
Peric V, Zilic S, Srebric M, Mikic A (2011). Nutritional value of the grain of Kunitz-free soybean cultivars. Biotechnology in Animal Husbandry 27(4):1537-1542. https://doi.org/10.2298/BAH1104537P

Pesic M, Vucelic-Radovic B, Barac M, Stanojevic S, Nedovic V (2007). Influence of different genotypes on trypsin inhibitor levels and activity in soybeans. Sensors 7(1):67-74.

Tan-Wilson AL, Chen JC, Duggan MC, Chapman C, Obach RS, Wilson KA (1987). Soybean Bowman-Birk trypsin isoinhibitors: classification and report of a glycine rich trypsin inhibitor class. Journal of Agriculture and Food Chemistry 35:974-981.
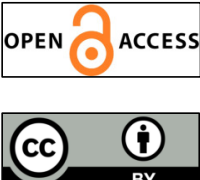

The journal offers free, immediate, and unrestricted access to peer-reviewed research and scholarly work. Users are allowed to read, download, copy, distribute, print, search, or link to the full texts of the articles, or use them for any other lawful purpose, without asking prior permission from the publisher or the author.

License - Articles published in Notulae Scientia Biologicae are Open-Access, distributed under the terms and conditions of the Creative Commons Attribution (CC BY 4.0) License.

(c) Articles by the authors; SHST, Cluj-Napoca, Romania. The journal allows the author(s) to hold the copyright/to retain publishing rights without restriction. 